\title{
Keberadaan Orkes Keroncong KKAJ Di Jombang
}

\author{
Antisipasi Iman Nehe \\ Program Studi Seni Musik Fakultas Bahasa dan Seni Universitas Negeri Surabaya \\ E-Mail: Imannehe38@gmail.com
}

\begin{abstract}
The researcher discusses the existence of the KKAJ Keroncong Orchestra based on the interests of researchers with the motivation to preserve and maintain keroncong music, especially in Jombang Regency. The KKAJ keroncong orchestra plays an important role in the development of keroncong music in Jombang and is one of the orchestras that exists and is active among other orchestras in Jombang Regency. The existence of the keroncong orchestra also has a significant influence with the emergence and growth of other keroncong orchestras in Jombang. The objective of the researcher is to discuss the existence of the KKAJ Keroncong Orchestra to obtain information on the background, developments, and regeneration efforts of the KKAJ keroncong orchestra in Jombang so that they can continue to exist. The method used in this study is a qualitative research method with the aim of obtaining descriptive data in the form of written and oral words. In collecting data and information, researchers use primary and secondary sources. The results of the study were obtained through observation, interviews, and documentation. The results showed that the existence of the KKAJ keroncong orchestra in Jombang was an individual desire namely Achmad Yani's desire to form a keroncong orchestra with the aim of preserving and maintaining it. Starting in 2007 Achmad Yani bought keroncong musical instruments and invited old people around his house to form an orchestra and play the instruments. Keroncong Orchestra in 2007 did not yet have a name, the name of the KKAJ Keroncong Orchestra was only formed in 2012. The development of the KKAJ keroncong orchestra in Jombang is a fairly rapid development, both developments in membership, complete musical instruments, and the abilities of the musicians. The musicians of the KKAJ keroncong orchestra have a very important role in determining the steps or actions so that the KKAJ keroncong orchestra does not stop or continue. Steps taken for regeneration efforts are recruiting and opening violin lessons.
\end{abstract}

Keywords: Existence, Keroncong Orchestra, Development, Regeneration.

\begin{abstract}
Abstrak: Peneliti membahas Keberadaan Orkes Keroncong KKAJ didasari dengan ketertarikan peneliti dengan motivasi melestarikan dan mempertahankan musik keroncong khususnya di Kabupaten Jombang. Orkes keroncong KKAJ sangat berperan dalam perkembangan musik keroncong di Jombang dan merupakan salah satu orkes yang eksis dan aktif diantara orkes-orkes lain di Kabupaten Jombang. Keberadaan orkes keroncong juga memiliki pengaruh brsar dengan munculnya dan bertumbuhnya orkes-orkes keroncong lain di Kabupaten Jombang. Tujuan peneliti membahas Keberadaan Orkes Keroncong KKAJ untuk memperoleh informasi data mengenai latar belakang, perkembangan, dan upaya regenerasi yang dilakukan orkes keroncong KKAJ di Jombang sehingga dapat tetap eksis. Metode yang digunakan dalam penelitian ini adalah metode penelitian kualitatif dengan tujuan memperoleh data deskriptif berupa kata-kata tertulis dan lisan. Dalam pengumpulan data dan informasi, peneliti menggunakan sumber primer dan sekunder. Hasil penelitian diperoleh melalui observasi, wawancara, dan dokumentasi. Hasil penelitian menunjukan bahwa keberadaan orkes keroncong KKAJ di Jombang merupakan keinginan individu yaitu keinginan Achmad Yani untuk membentuk orkes keroncong dengan tujuan melestarikan dan mempertahankannya. Berawal pada tahun 2007 Achmad Yani membeli alat-alat musik keroncong dan mengajak orang-orang tua di sekitar rumahnya untuk membentuk orkes dan memainkan alat-alat musik tersebut. Orkes keroncong tahun 2007 belum memiliki nama, nama orkes keroncong KKAJ baru terbentuk pada tahun 2012. Perkembangan orkes keroncong KKAJ di Jombang merupakan perkembangan yang cukup pesat, baik perkembangan dalam keanggotaan, lengkapnya alat-alat musik, maupun kemampuan para musisi-musisinya. Para musisi orkes keroncong KKAJ mempunyai peranan yang sangat penting guna menentukan langkah-langkah atau tindakan agar orkes keroncong KKAJ tidak terhenti atau tetap ada yang melanjutkan. Langkah-langkah yang dilakukan untuk upaya regenerasi adalah melakukan perekrutan dan membuka les biola.
\end{abstract}

Kata kunci: Eksistensi, Orkes Keroncong, Perkembangan, Regenerasi. 


\section{PENDAHULUAN}

Musik keroncong adalah jenis permainan musik tradisional yang menggunakan tangga nada diatonik dengan iringan beberapa alat musik berdawai yang dimainkan dengan aturan tertentu sehingga menjadi ciri khas musik itu sendiri, Soeharto (1996:45).

Musik keroncong telah menjadi bagian dari budaya musik Indonesia. Musik keroncong memiliki karakteristik tersendiri yang berbeda dengan musik lainnya dan mengandung nilai-nilai budaya bangsa Indonesia. Musik keroncong saat ini mungkin dianggap kuno atau dianggap ketinggalan zaman. Karena bila diperhatikan saat ini khususnya di kalangan anak-anak muda, mereka lebih tertarik terhadap musik-musik saat ini seperti musik pop dan musik elektronik dibanding musik keroncong. Tetapi meskipun musik keroncong saat ini mungkin dianggap kuno atau ketinggalan zaman, masih banyak upayaupaya yang berusaha untuk melestarikan musik keroncong dan tidak sedikit juga yang masih tertarik terhadap musik keroncong saat ini. Dibuktikan dengan ada banyak kelompokkelompok atau orkes keroncong di kalangan masyarakat dan orang-orang yang setidaknya sebatas penikmat musik. Musik keroncong bisa dikatakan masih bisa diterima dan bisa dinikmati oleh semua orang dan semua kalangan.

Gaya dan lirik musik keroncong dapat dikatakan mengalami perubahan dari masa ke masa. Jika pada masa keroncong tempo dulu lirik lagu keroncong masih berkisah mengenai cerita rakyat dan lebih sederhana. Sedangkan saat ini bila diperhatikan lirik lagu keroncong menyesuaikan perkembangan musik pop dan selera lokal masyarakat, serta musik keroncong saat ini cenderung tidak terpaku pada pakem musik keroncong.

Perkembangan musik keroncong sangat beragam, mereka para pemusik arranger, pencipta, maupun penyanyi merupakan musisimusisi yang mempelopori perkembangan musik keroncong ini. Kota Jakarta, Semarang, Yogyakarta dan Surakarta maupun Surabaya merupakan kota-kota tempat tumbuh dan berkembangnya musik keroncong.

Selain kota-kota besar yang menjadi tempat bertumbuh dan berkembangnya musik keroncong, Kabupaten Jombang juga salah satu di antaranya. Menurut Ketua Pamori Jawa Timur, Bambang Suharto kepada Blitartimes, Selasa (27/2/2018), Kabupaten Jombang menjadi yang terbaik di Jawa Timur untuk perkembangan musik keroncong. Hal itu disebabkan pemertintah daerah Jombang memasukkan musik keroncong ke dalam kurikulum pendidikan. Di Kabupaten Jombang ini anak-anak muda banyak yang suka main musik keroncong.

Sebelum adanya kebudayaan musik keroncong di Jombang, Kabupaten Jombang terlebih dahulu terkenal dengan beberapa kebudayaan seperti Besutan, Ludruk Jombangan, Remo Bolet, dan Wayang Topeng Jatiduwur. Jadi, dapat dikatakan bahwa keberadaan musik keroncong di Kabupaten Jombang merupakan hal yang baru di sana. Keberadaan musik keroncong di Jombang tentunya tidak lepas dari usaha-usaha dan upaya-upaya para seniman atau musisimusisi untuk mengembangkan dan melestarikan musik keroncong di Kabupaten Jombang. Salah satu musisi yang beperan dalam perkembangan musik keroncong di Jombang adalah Achmad Yani. Beliau adalah pemimpin sekaligus pendiri orkes keroncong KKAJ (Komunitas Keroncong Anak Jombang) di Jombang.

Seperti yang dikatakan Ketua Pamori Jawa Timur, Bambang Suharto kepada Blitartimes, Selasa (27/2/2018), pendidikan di Kabupaten Jombang dalam kurikulumnya memasukkan musik keroncong untuk dijadikan sebagai kegiatan ekstrakurikuler siswa. Adapun orkes keroncong yang berasal dari ekstrakurikuler sekolah adalah: orkes keroncong Kromansa Joe SMAN 1 Jombang, orkes keroncong RECORDA (Regu Keroncong SMA 2 Jombang), dan orkes keroncong SMAGA JOE (SMAN 3 Jombang). Orkes-orkes ini juga aktif dalam kegiatankegiatan dan acara-acara di Kabupaten Jombang.

Salah satu orkes keroncong yang menonjol dan berkembang di Kabupaten Jombang adalah orkes keroncong "KKAJ (Komunitas Keroncong Anak Jombang)". Orkes ini tidak hanya tampil di Kabupaten Jombang saja melainkan juga tampil di kota-kota lain untuk acara-acara hiburan.

Orkes keroncong KKAJ ini didirikan dengan tujuan mempertahankan dan melestarikan musik keroncong khususnya di Kabupaten Jombang. Orkes keroncong KKAJ adalah perkumpulan pecinta musik keroncong yang anggotanya adalah para pelajar SMP dan SMA bahkan anak-anak SD di Kabupaten Jombang. Orkes keroncong KKAJ sudah banyak mengikuti dan tampil di beberapa event, mulai dari event kecil-kecilan dan acara-acara hiburan serta tampil pada acara-acara pernikahan hingga tampil dan mengisi acara di televisi lokal. 
Bukan hanya itu mereka juga pernah menjuarai festival musik keroncong yang dilangsungkan di Amphitheatre Sekolah Pilar Indonesia di Jalan Dewa No. 9, Ciangsana Kawasan Cibubur, Bogor yang dimeriahkan oleh Penyanyi Iwan Fals, Kaka Slank, Tika Bisono dan legenda musik keroncong Indonesia, Waldjinah pada tahun 2015. Festival Orkes Keroncong Anak Muda saat itu mengusung tema antinarkoba "Say No to Drugs, Say Yes to Keroncong".

Keberadaan orkes keroncong KKAJ di Jombang memiliki pengaruh yang besar dalam bertumbuhnya orkes-orkes keroncong lain di Kabupaten Jombang seperti orkes-orkes keroncong di sekolah-sekolah. Berawal ketika Bapak Achmad Yani selaku pemimpin orkes KKAJ beserta anggota-anggota orkes KKAJ mengajar musik keroncong di sekolah-sekolah dalam kegiatan ekstrakurikuler. Sekolah-sekolah tersebut adalah: SMAN 2 Jombang, dan SMPN 2 Jombang. Saat itu juga ada dari SMAN 3 Jombang, tetapi tidak melalui kegiatan ekstrakurikuler melainkan siswa-siswa SMAN 3 Jombang datang sendiri ke KKAJ untuk belajar musik keroncong. oleh sebab itu, dapat dikatakan bahwa munculnya orkes-orkes keroncong lain di Kabupaten Jombang tidak terlepas dari pengaruh keberadaan orkes keroncong KKAJ.

\section{METODE}

metode penelitian pada dasarnya merupakan cara ilmiah untuk mendapatkan data dengan tujuan dan kegunaan tertentu dimana cara ilmiah tersebut mengandung arti bahwa kegiatan penelitian tersebut didasarkan pada ciri-ciri keilmuan yaitu rasional, empiris, dan sistematis, Sugiyono (2010:9). Penelitian kualitatif adalah "prosedur penelitian yang menghasilkan data deskriptif berupa kata-kata tertulis atau lisan dari orang-orang dan prilaku yang dapat diamati”. Penelitian kualitatif bertumpu pada latar belakang alamiah secara holistik, memposisikan manusia sebagai alat penelitian, melakukan analisis data secara induktif, lebih mementingkan proses daripada hasil penelitian yang dilakukan disepakati oleh peneliti dan subjek penelitian, Bogdan dan Taylor dalam Moleong (2010, hlm. 4).

\section{PEMBAHASAN}

\section{Latar Belakang Orkes Keroncong KKAJ}

Orkes keroncong KKAJ (Komunitas Keroncong Anak Jombang). beralamat di Perum Cacat Veteran No 1 Jombang. Orkes keroncong dari Kabupaten Jombang ini didirikan oleh Achmad Yani dan merupakan keinginan individu yaitu, berawal dari ketertarikannya pada musik keroncong, pada tahun 2007 Achmad Yani membeli alat-alat musik keroncong dan membuat perkumpulan dengan orang-orang tua dari sekitar rumah Achmad Yani untuk memainkan alat-alat musik tersebut. Formasi orkes keroncong tahun 2007 sebagai berikut:

Tabel 1 Formasi awal orkes keroncong tahun 2007

\begin{tabular}{|l|l|l|}
\hline No & Nama & Instrumen \\
\hline 1 & Achmad Yani & Gitar \\
\hline 2 & Wakit & Cak \\
\hline 3 & Totok & Cuk \\
\hline 4 & Ngatiman & Cello \\
\hline 5 & Yayan & Bass \\
\hline 6 & Rusli, Dea, Saipul & Biola \\
\hline 7 & Nanang & Flute \\
\hline
\end{tabular}

Setelah kurang lebih dua tahun berjalan, ada beberapa anggota yang meninggal dunia. Akhirnya tahun 2010 Achmad Yani mendatangkan guru, beliau adalah Rusli seorang guru biola. Rusli diminta untuk mengajar biola dan mengajar not balok serta mengajar untuk menggunakan software musik. software yang digunakan saat itu adalah gitar pro dan finale. Setelah beberapa waktu rusli mengajar, dan akhirnya Achmad Yani mendownload buku metode violin suzuki untuk digunakan sebagai materi pembelajaran dan materi latihan.

Pada awalnya orkes keroncong ini diberi nama Keroncong Anak, dan sesuai namanya orkes keroncong ini beranggotakan anak-anak dan dilatih oleh Rusli. Saat itu pemain musik dan penyanyi direkrut melalui sekolah-sekolah. Penampilan pertama kali orkes Keroncong Anak dilaksanakan pada acara pemerintah daerah Jombang pada bulan Juli 2012, dan tiga bulan kemudian tampil di kota Jakarta pada tanggal 3 Oktober 2012, dan ini pertama kali tampil di luar kota. Pada tanggal 3 Oktober 2012, nama orkes keroncong anak diganti dengan Komunitas Keroncong Anak Simphoni Violin School seperti yang tertera pada piagam penghargaan yang di peroleh. Tetapi, menurut Achmad Yani selaku pendiri orkes keroncong tersebut menilai bahwa nama baru yang tertera di piagam penghargaan tersebut merupakan kesalahan, yaitu salah ketik oleh pihak acara. Akhirnya pada tanggal yang sama, nama orkes keroncong ini diganti menjadi orkes keroncong KKAJ (Komunitas Keroncong Anak Jombang). Dan ini merupakan awal mula terbentuknya nama orkes keroncong KKAJ. Tahun 2012 merupakan tahun dimana orkes keroncong KKAJ sudah mulai sering tampil di 
luar kota seperti kota Solo dan Semarang, dan setiap ada perlombaan di mana pun orkes keroncong KKAJ selalu ikut berpartisipasi.

Tahun 2010 merupakan tahun dimana orkes keroncong KKAJ mulai banyak diminati dan diikuti oleh anak-anak di Kabupaten Jombang untuk belajar musik keroncong. Tetapi, tidak semua memiliki instrumen khususnya alat musik biola. Sehingga tahun 2010-2011, achmad yani selaku pendiri orkes keroncong KKAJ berinisiatif membuat sendiri alat musik biola dengan bahan kayu dan triplek. Sedangkan untuk rambut bow Achmad Yani membuatnya dari bahan tali pancing no 40.

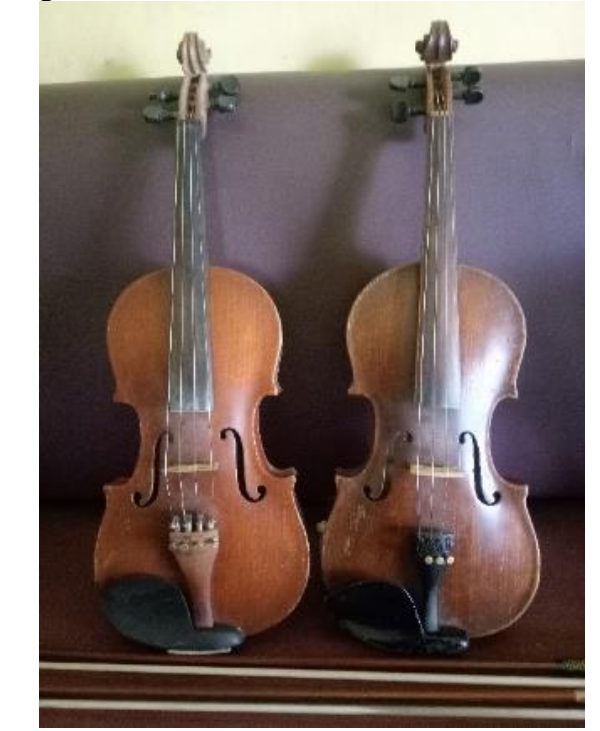

Gambar 1 biola buatan tangan Achmad Yani

(Dok. Iman: 2019)

Gambar di atas merupakan potret alat musik biola buatan tangan Achmad Yani pada tahun 2010 ketika pemain biola orkes keroncong KKAJ kekurangan alat. Sebelum Achmad Yani membuat biola dari bahan kayu, biola dibuat dengan dari bahan triplek dan membuat rambut bow dari bahan tali pancing.

Tahun 2017 sebelum orkes keroncong KKAJ menggunakan flute, Achmad Yani membuat suling dari bahan pipa paralon kecil seukuran flute. Tahun 2012 setelah anak-anak orkes keroncong KKAJ sudah bisa dan mahir bermain biola, akhirnya Achmad Yani mulai membeli alat-alat musik biola dengan harga berkisar Rp. 500.000.

Latihan orkes keroncong KKAJ dilaksanakan setiap hari Sabtu pukul 19.00-22.00. Tetapi jika ada even, orkes keroncong KKAJ berlatih setiap hari pukul 19.00-22.00.

Materi-materi lagu yang dibawakan orkes keroncong KKAJ tergantung pada tema acara yang diikuti. Acara-acara yang biasanya diikuti adalah: acara pernikahan dan acara keagamaan yang meliputi acara keagamaan islam dan kristen. Salah satu materi lagu yang dibawakan orkes keroncong KKAJ pada acara keagamaan islam adalah lagu "assalamualaikum" dan untuk acara keagamaan kristen biasanya membawakan lagu "El Shaddai". sedangkan untuk acara pernikahan biasanya membawakan lagu "Dia-Anji"

\section{Perkembangan Orkes Keroncong KKAJ}

Orkes keroncong KKAJ mengalami perkembangan dari tahun ke tahun dan merupakan perkembangan yang cukup pesat, baik perkembangan dalam keanggotaan, lengkapnya alat musik keroncong maupun kemampuan para musisi-musisinya.. Pada tahun 2010 orkes keroncong KKAJ dibentuk dengan dengan nama Orkes Keroncong Anak. Saat inilah orkes keroncong KKAJ kekurangan pemain biola dan flute. Anggota pada saat itu masih pemula dan lebih banyak anak-anak, materi latihan yang digunakan adalah metode violin suzuki satu sampai sepuluh. Orkes keroncong KKAJ menggunakan aplikasi musik sebagai media untuk menulis dan mengaransemen lagu-lagu. Aplikasi yang digunakan pada saat itu adalah gitar pro dan finale. Orkes keroncong KKAJ pada tahun 2011 sudah mulai tampil pada acara-acara hiburan di pendopo-pendopo, seperti acara-acara pernikahan.

Tahun 2012 Achmad Yani dan anggotaanggota orkes keroncong KKAJ mulai mengajar musik keroncong di sekolah-sekolah pada kegiatan ekstrakurikuler dan tahun 2012 juga nama orkes keroncong KKAJ baru terbentuk yaitu pada tanggal 3 Oktober ketika orkes keroncong KKAJ tampil pertama kali di luar kota yakni Jakarta. Formasi orkes keroncong KKAJ tahun 2012 sebagai berikut:

Tabel 2 Formasi orkes keroncong anak 2012

\begin{tabular}{|l|l|l|}
\hline No & Nama & Instrumen \\
\hline 1 & Afan & Gitar \\
\hline 2 & Wakit & Cak \\
\hline 3 & Agung & Cuk \\
\hline 4 & Yanu & Cello \\
\hline 5 & Vian & Bass \\
\hline 6 & $\begin{array}{l}\text { Lia, Dibta, Beta, Bita, } \\
\text { Dea, Faradiba, Gisna, } \\
\text { Pasha, Dinda, Delia, Bela, } \\
\text { Benedo, Aldo, Dwi, Vega, } \\
\text { Arum, Luis }\end{array}$ & Biola \\
\hline 7 & Ilham & Cello gesek \\
\hline 8 & Nanang & Flute \\
\hline 9 & Sita, Sinta & Vokalis \\
\hline
\end{tabular}


Tahun 2019 orkes keroncong KKAJ mulai tampil mengisi acara stasiun televisi lokal yaitu TVRI Jawa Timur. Orkes keroncong KKAJ pada tahun 2013 sudah mulai tampil pada kegiatan dan perlombaan di luar kota seperti kota Solo, Semarang, dan Jakarta.

\section{Upaya Regenerasi yang Dilakukan Orkes Keroncong KKAJ}

Para musisi orkes keroncong KKAJ mempunyai peranan yang sangat penting guna menentukan langkah-langkah atau tindakan agar orkes keroncong KKAJ tidak terhenti atau tetap ada yang melanjutkan. Langkah-langkah tersebut adalah melakukan perekrutan dan membuka les biola. Objek yang menjadi tujuan perekrutan adalah sekolah-sekolah. Beberapa sekolah di Jombang menjadi tujuan musisi orkes keroncong KKAJ untuk mencari anggota baru kerena memiliki kegiatan ekstrakurikuler musik keroncong yang dilatih oleh Achmad Yani selaku pendiri orkes keroncong KKAJ dan anggotaanggota orkes keroncong KKAJ. sekolah-sekolah tersebut adalah SMAN 2 Jombang, SMPN 2 Jombang, SMAN 1 Jombang, dan SMAN 3 Jombang. Jadi, lebih mudah bagi mereka melakukan perekrutan karena mereka memiliki ikatan dengan kegiatan ekstrakurikuler di sekolah tersebut.

Tahun 2010 Achmad Yani selaku pendiri orkes keroncong KKAJ membuka les biola dengan tujuan untuk mencari peminat alat musik biola yang kemudian dijadikan sebagai anggota dan pemain biola orkes keroncong KKAJ. Dari 17 murid les biola, yang menjadi anggota orkes keroncong KKAJ berjumlah 5 murid.

dari upaya yang dilakukan musisi-musisi orkes keroncong KKAJ, adapun faktor penghambat yang menjadi kendala proses regenerasi tersebut adalah full day school. Menurut Achmad Yani selaku pendiri dan pemimpin orkes keroncong KKAJ satu-satunya faktor penghambat regenerasi adalah full day school, karena menurut beliau tidak ada waktu buat anak-anak untuk latihan dan tidak ada waktu untuk mengikuti kegiatan-kegiatan orkes keroncong KKAJ, dan selain itu berhubung dengan anak-anak sekolah yang menjadi objek perekrutan anggota baru.

Faktor-faktor yang Mendukung Keberadaan Orkes Keroncong KKAJ di Jombang

Keberadaan orkes keroncong KKAJ di Jombang tentunya tidak terlepas dari berbagai hal untuk mendukung dalam berbagai aspek. Hal-hal yang mendukung keberadaan orkes keroncong
KKAJ di Jombang adalah: organisasi; bentuk penyajian yang meliputi tata suara, tata panggung, tata rias, busana dan tempat latihan.

\section{Organisasi Orkes Keroncong KKAJ}

Struktur organisasi orkes keroncong KKAJ mengalami pergantian dari tahun 20122019. Pergantian dilakukan karena beberapa pengurus organisasi yang kuliah di luar kota. Struktur organisasi orkes keroncong KKAJ yaitu sebagai berikut:

Tabel 3 Struktur organisasi orkes keroncong KKAJ

\begin{tabular}{|c|l|c|c|c|}
\hline No & Nama & Ketua & Bendahara & sekretaris \\
\hline 1 & $2012-$ & Rendi & Nina & Nina \\
& 2015 & & & \\
\hline 2 & $\begin{array}{l}2015- \\
2017\end{array}$ & Haikal & Hana & Hana \\
\hline 3 & $\begin{array}{l}2017- \\
2018\end{array}$ & Ayub & Hana & Hana \\
\hline 4 & $\begin{array}{l}2018- \\
2019\end{array}$ & Ayub & Agis & Agis \\
\hline
\end{tabular}

\section{Bentuk Penyajian}

Pertunjukan musik dalam penyajiannya terdapat beberapa unsur yang menjadikan pertunjukan itu menarik untuk ditonton. Penyajian pertunjukan orkes keroncong KKAJ meliputi tata suara, tata panggung, tata rias, busana dan tempat latihan.

Dalam penataan suara dari pertunjukan orkes keroncong KKAJ memakai sound system lengkap yaitu mixer, sound, kabel dan mikrofon. Untuk output beberapa alat musik menggunakan pick up yang langsung ditempel pada alat musik. Berikut salah contoh penempatan pick up pada alat musik keroncong orkes keroncong KKAJ:

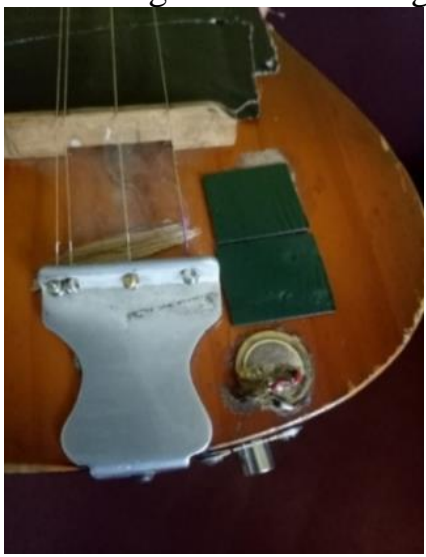

Gambar 2 penempatan pick up untuk alat musik cak (dok. Iman: 2019)

Letak dan posisi panggung untuk orkes keroncong KKAJ disesuaikan dengan ukuran panggung dan banyaknya pemain. Orkes keroncong KKAJ memiliki beberapa pemain yakni: biola, flute, cak, cuk, cello, gitar, bass, dan vokal. 
Tata rias yang digunakan oleh anggota orkes keroncong KKAJ terutama perempuan merupakan tata rias sederhana, tata rias meliputi pemakaian bedak, pensil alis, dan lipstick. Hal ini diperlukan dengan tujun agar wajah terlihat cerah dan cantik. Dalam persiapan untuk tata rias tidak menggunakan jasa rias salon, melainkan berdandan sendiri seperti kebanyakan wanita yang berdandan sehari-hari. Hal ini dilakukan untuk tidak mengeluarkan banyak biaya.

Orkes keroncong KKAJ dalam setiap penampilannya selalu menyajikan gaya busana yang berbeda-beda dalam setiap acara, tergantung tema acara dan permintaan. Orkes keroncong KKAJ menyediakan beberapa kostum yang bervariasi yang menyesuaikan dengan tema acara yang dihadiri, dan beberapa busana dijahit sendiri oleh isteri Achmad Yani selaku pendiri orkes keroncong KKAJ supaya tidak memerlukan banyak biaya untuk penyewaan busana

Tempat yang digunakan sebagai tempat latihan orkes keroncong KKAJ tidak berada di dalam ruangan, melainkan berada di luar ruangan yakni di samping rumah Achmad Yani selaku pendiri orkes keroncong KKAJ yang berada di Perum Cacat Veteran No 1 Jombang. Di bagian atas tempat latihan ditutup dengan atap dengan tujuan melindungi dari panas dan hujan, sehingga ketika hujan dan panas pun anak-anak orkes keroncong KKAJ dapat berlatih dengan nyaman.

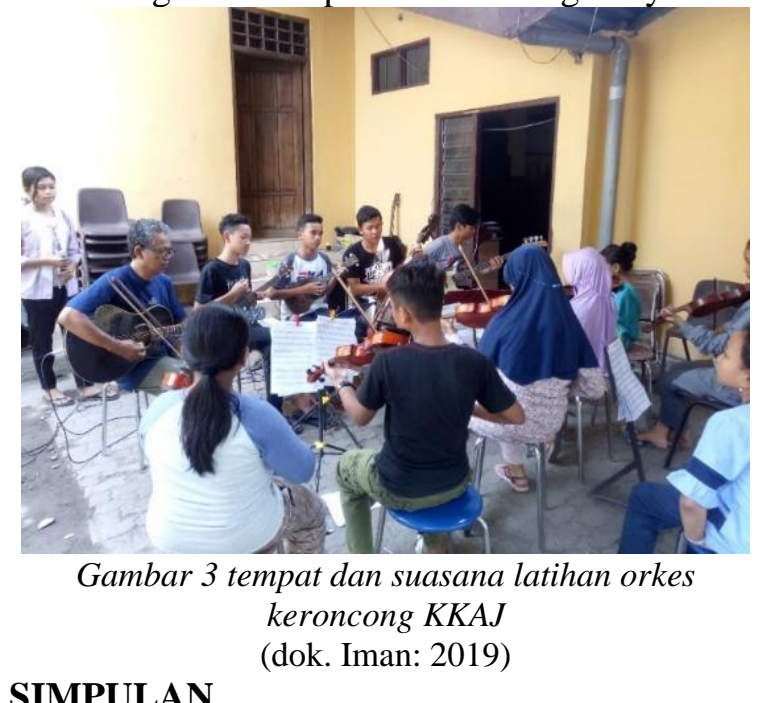

SIMPULAN

Berdasarkan hasil penelitian dan pembahasan, peneliti menyimpulkan bahwa keberadaan orkes keroncong KKAJ di Jombang bertujuan untuk melestarikan musik keroncong khususnya di Kabupaten Jombang dan dengan itu supaya orkes keroncong KKAJ tetap bertahan. Keroncong KKAJ menjadi wadah untuk belajar dan berlatih musik keroncong bagi mereka yang mencintai musik keroncong di Kabupaten Jombang terutama pemuda dan anak-anak sekolah. Berawal pada tahun 2007 Achmad Yani membeli alat-alat musik keroncong dan membuat perkumpulan dengan orang-orang tua dari sekitar rumah Achmad Yani untuk memainkan alat-alat musik tersebut dan orkes keroncong saat itu belum memiliki nama. Orang-orang yang berperan dalam terbentuknya orkes keroncong tahun 2007 adalah Achmad Yani, Wakit, Totok, Ngatiman, Yayan, Rusli, Dea, Saipul, dan Nanang. Nama orkes keroncong KKAJ terbentuk ketika orkes keroncong KKAJ tampil pertama kali di luar kota yakni di Jakarta pada tanggal 3 Oktober tahun 2012.

Orkes keroncong KKAJ mengalami perubahan dan perkembangan dari tahun ke tahun yaitu tahun 2010-2019 sebagai berikut: tahun 2010 orkes keroncong KKAJ dibentuk dengan dengan nama Orkes Keroncong Anak. Saat inilah orkes keroncong KKAJ kekurangan pemain biola dan flute. Anggota pada saat itu masih pemula dan lebih banyak anak-anak. Tahun 2011 sudah mulai tampil pada acara-acara hiburan di pendopo-pendopo, seperti acara-acara pernikahan. Tahun 2012-2019 Achmad Yani dan anggota-anggota orkes keroncong KKAJ mulai mengajar musik keroncong di sekolah-sekolah pada kegiatan ekstrakurikuler, dan tahun 2013 sudah mulai tampil pada acara dan perlombaan di luar kota seperti kota Solo, Semarang, dan Jakarta.

Musisi-musisi orkes keroncong KKAJ melakukan upaya regenerasi dengan langkah melakukan perekrutan dan membuka les biola. Objek yang menjadi tujuan perekrutan adalah sekolah-sekolah. Beberapa sekolah di Jombang menjadi tujuan musisi orkes keroncong KKAJ untuk mencari anggota baru kerena memiliki kegiatan ekstrakurikuler musik keroncong yang dilatih oleh Achmad Yani selaku pendiri orkes keroncong KKAJ dan anggota-anggota orkes keroncong KKAJ. Tahun 2010 Achmad Yani selaku pendiri orkes keroncong KKAJ membuka les biola dengan tujuan untuk mencari peminat alat musik biola yang kemudian dijadikan sebagai anggota dan pemain biola orkes keroncong KKAJ. Dari 17 murid les biola, yang menjadi anggota orkes keroncong KKAJ berjumlah 5 murid.

\section{DAFTAR PUSTAKA}

Abidin, zainal. 2007. Analisis Eksistensial. Jakarta: PT. Raja Grafindo Persada. 
Anggoro, Triadi. 2005. Eksistensi Grup Musik Keroncong Dipa Sakti Mojokerto. Skripsi tidak diterbitkan. Mojokerto: Universitas Negeri Surabaya

Alvianto, Wibi Ardi. 2012. Eksistensi Grup Musik Keroncong Gema Irama di Desa Gedongmulya Kecamatan Lasem. Skripsi tidak diterbitkan. Rembang: Universitas Negeri Semarang.

Banoe, Pono. 2003. Kamus Musik. Yogyakarta: Kanisius.

Departemen Pendidikan dan Kebudayaan. 1988. Kamus Besar Bahasa Indonesia. Jakarta: Balai Pustaka.

DEPDIKBUD. 1987. Peralatan Hiburan dan Kesenian Tradisional Daerah Jawa Barat. Jakarta: DEPDIKBUD Proyek Inventarisasi dan Dokumentasi Kebudayaan Daerah.

Hadi, Irfan Ariffianto. 2015. Eksistensi Waroeng Keroncong di Kota Semarang. Skripsi tidak diterbitkan. Semarang: Universitas Negeri Semarang.

Harmunah. 1987. Musik Keroncong: Sejarah, Gaya, dan Perkembangan. Yogyakarta: Pusat Musik Liturgi.

Jamalus, 1988. Pengajaran Musik Melalui Pengalaman Musik. Jakarta: Proyek Pengembangan Lembaga Pendidikan Tenaga Kependidikan.

Kornhauser, Bronia. 1978. Studies in Indonesian Music, Melbornue: Monesh University.

Matthenson, 1713. Das Neveroffenete Orkestre. Hamburg: Schiller.

Osborne, Loren $\mathrm{O}$ and Martin $\mathrm{H}$. Neumeyer dalam Taneko, Soleman B. 1984. Struktur dan Proses Sosial: Suatu Pengantar Sosiologi Pembangunan. Jakarta: CV. Rajawali.

Soeharto, dkk. 1996. Serba-serbi Keroncong. Jakarta: Mustika.

Syafiq, Muhammad. 2003. Ensiklopedia Musik Klasik. Yogyakarta: Adicita Karya Nusa. 